\title{
Expression of and correlation between BCL6 and ZEB family members in patients with breast cancer
}

\author{
LIN ANG $^{1}$, LI ZHENG $^{1}$, JIN WANG $^{1}$, JIN HUANG $^{1}$, HONG-GUANG HU $^{1}$, QIANG ZOU ${ }^{1}$, \\ YANG ZHAO $^{1}$, QIANG-MING LIU ${ }^{1}$, MIN ZHAO ${ }^{1}$ and ZHENG-SHENG WU ${ }^{2}$ \\ ${ }^{1}$ Department of Pathology, The Second People's Hospital of Hefei, Hefei, Anhui 230011; \\ ${ }^{2}$ Department of Pathology, Anhui Medical University, Hefei, Anhui 230000, P.R. China
}

Received May 5, 2016; Accepted March 23, 2017

DOI: $10.3892 / \mathrm{etm} .2017 .5101$

\begin{abstract}
B-cell lymphoma 6 (BCL6), a proto-oncogene, is an evolutionarily conserved zinc finger protein that functions as a transcriptional repressor. BCL6 is the master regulator of B-lymphocyte development, and it has been reported that BCL6 may serve an important role in breast cancer progression. The aim of the present study was to investigate the expression of BCL6, zinc finger E-box-binding homeobox (ZEB)1 and ZEB2 and their associations in breast cancer. The mRNA and protein expression of BCL6, ZEB1 and ZEB2 was assessed using in situ hybridization and immunohistochemistry, respectively, in 228 patients with breast cancer and 80 patients with benign breast disease. In addition, the association between BCL6, ZEB1 and ZEB2 expression and the clinicopathological characteristics and survival of patients with breast cancer were analyzed. The mRNA and protein expression of BCL6, ZEB1 and ZEB2 were significantly higher in breast cancer tissues compared with benign breast disease tissues $(\mathrm{P}<0.05)$. The expression of BCL6, ZEB1 and ZEB2 were significantly positively correlated with tumor size, lymph node metastasis and a higher tumor stage $(\mathrm{P}<0.05)$. Furthermore, patients with BCL6, ZEB1 and ZEB2 protein-positive primary tumors had significantly lower overall survival ( $\mathrm{P}=0.001,0.002$ and 0.001 , respectively) and relapse-free survival $(\mathrm{P}=0.002,0.001$ and 0.003 , respectively) rates. The mRNA expressions of ZEB1 $\left(r_{\mathrm{s}}=0.326, \mathrm{P}<0.001\right)$ and ZEB2 $\left(r_{\mathrm{s}}=0.382, \mathrm{P}<0.001\right)$ were significantly positively correlated with BCL6 mRNA expression, and the protein expressions of ZEB1 $\left(\left(r_{\mathrm{s}}=0.449, \mathrm{P}<0.001\right)\right.$ and ZEB2 $\left(r_{\mathrm{s}}=0.669\right.$, $\mathrm{P}<0.001)$ were significantly positively correlated with BCL6 protein expression. These results suggest that BCL6, ZEB1
\end{abstract}

Correspondence to: Dr Min Zhao, Department of Pathology, The Second People's Hospital of Hefei, 246 Heping Road, Hefei, Anhui 230011, P.R. China

E-mail: zhao.min.hi@163.com

Key words: breast neoplasm, B-cell lymphoma 6, zinc finger E-box-binding homeobox family, in situ hybridization, immunohistochemistry and ZEB2 are potential biomarkers for the invasion, metastasis and prognosis of breast cancer, and that BCL6 may be a regulator of the ZEB family.

\section{Introduction}

Despite considerable progresses in diagnostic and therapeutic approaches in recent years, breast cancer remains the most common malignant tumor in women worldwide (1). In the United States of America, breast cancer accounts for $29 \%$ of all new cancer cases in women annually (2). Tumor invasion and metastasis are multistep, dynamic and complex processes, which contribute to the vast majority of breast cancer-associated mortalities (3). Previous studies have demonstrated that B-cell lymphoma 6 (BCL6) serves an important role in breast cancer invasion and metastasis (4-6). The oncogenic transcriptional modulator BCL6 is a master regulator of B-lymphocyte development and growth, and, in addition to facilitating the proliferation of B-lymphocytes and inhibiting their differentiation into plasma and memory B cells (7), BCL6 has been reported to prevent the differentiation of mammary cells (8) and stimulate the oncogenicity of human breast cancer cells (4).

The zinc finger E-box-binding homeobox (ZEB) family includes ZEB1 and ZEB2, which are important nuclear transcription factors and have been reported to be key factors in epithelial-mesenchymal transition (EMT) $(9,10)$. EMT is recognized as an important process in the invasion and metastasis of cancer cells (11), and loss of the epithelial marker E-cadherin is considered to be a hallmark of EMT. ZEB1 and ZEB2 are able to induce the initiation of EMT by binding to the E-box sequence on the E-cadherin promoter, thus repressing its expression (12). A recent study demonstrated that BCL6 facilitates EMT by enhancing the ZEB1-mediated transcriptional repression of E-cadherin, promoting the invasion, migration and growth of breast cancer cells (13). The role of BCL6, ZEB1 and ZEB2 in different tumor types have been widely studied; however, little is currently known about the effects of and relationships between their expressions in breast cancer.

In the present study, the mRNA and protein expression of BCL6, ZEB1 and ZEB2 was assessed using in situ hybridization and immunohistochemical (IHC) analysis, respectively, 
in the breast tissue of 228 patients with breast cancer and 80 patients with benign breast disease. The association between BCL6, ZEB1 and ZEB2 expression with the clinicopathological characteristics and prognosis of patients with breast cancer was also investigated. Finally, the association between the expression of BCL6, ZEB1 and ZEB2 in breast cancer was assessed.

\section{Materials and methods}

Patients and specimens. A total of 228 consecutive female patients with breast cancer (range, 30-81 years; mean, 51.0 years) and 80 consecutive female patients with benign breast disease (range, 18-57 years; mean, 37.5 years) were enrolled in the present study, all of whom underwent radical mastectomy or modified radical mastectomy at The Second People's Hospital of Hefei (Hefei, China) or the First Affiliated Hospital of Anhui Medical University (Anhui, China) between May 2002 and November 2014. Patients with breast cancer who underwent chemotherapy or radiation therapy prior to surgery, or who had rheumatic disease, acute infection, human immunodeficiency virus infection or other types of cancer were excluded. Complete follow-up data was available for 197 patients, with a median follow-up time of 60 months. The histological grade of cancerous tissues was based on the World Health Organization classification of tumors (14), and the pathological tumor stage was defined according to the sixth edition of the tumor-node-metastasis classification of the International Union Against Cancer (15). Estrogen receptor, progesterone receptor and erb-b2 receptor tyrosine kinase 2 (c-erbB-2) expression levels were obtained from patients' pathology records. Levels were measured by immunohistochemistry scoring: For ER and PR expression, a percentage of stained tumor cells $>5 \%$ was considered positive (16); for c-erbB-2 expression, membrane staining intensity and pattern were measured as follows: 0 , completely negative or membrane positivity in $<10 \%$ of tumor cells; ,$+>10 \%$ of tumor cells had incomplete faint membrane positivity;,$++>10 \%$ of tumor cells had complete moderate membrane positivity; and,$+++>10 \%$ of tumor cells had complete strong circumferential membrane positivity (17). All tissue specimens collected during surgery were formalin-fixed, paraffin-embedded and cut into 4 - $\mu$ m-thick sections. The protocol used in the present study was approved by the Institutional Review Boards of the Second People's Hospital of Hefei and the First Affiliated Hospital of Anhui Medical University, and informed consent was provided by all patients.

In situ hybridization. In situ hybridization analyses of BCL6, ZEB1 and ZEB2 mRNA expression was performed using human BCL6, ZEB1 and ZEB2 ISH detection kit (MK1301-h, MK3730-h, and MK3731-h, Boshide Biotech Co., Ltd., Wuhan, Hubei, China). Three digoxin-labeled antisense oligonucleotide DNA probes for human BCL6, ZEB1 and ZEB2 were obtained from Boshide Biotech Co., Ltd. (Wuhan, China). The probe sequences were as follows: BCL6, 5'-GACAGCTGTATCCAGTTCACCCGCCATGCC AGTGA-3', 5'-TTCTATAGCATCTTTACAGACCAGTTG AAATGCAA-3', and 5'-ATCCTGCAGATGGAGCATGTT
GTGGACAGTTGCCG-3'; ZEB1, 5'-TGTAATCGTAAA TTCAAATGCACTGAGTGTGGAAA-3', 5'-TGGTTTGAA AAGATGCAAGCTGGACAGATTTCAGT-3', and 5'-TAT TCTCAACACATGAATCATCGCTACTCCTACTG-3'; and ZEB2, 5'-TACTATGCTATGAACATGGAGCCCAACTCC GATGA-3', 5'-AAGGAATTTTCAAATTCAAATAATCTG GACAACAA-3', and 5'-ATGAACCGGGCTTACTTGCAG AGCATTACCCCTCA-3'. All the materials used for in situ hybridization were autoclaved and treated with $0.1 \%$ diethyl pyrocarbonate-double distilled water $\left(\mathrm{DEPC}-\mathrm{ddH}_{2} \mathrm{O}\right)$ for $24 \mathrm{~h}$ at room temperature, and all solutions were prepared with $0.1 \%$ DEPC-dd $\mathrm{H}_{2} \mathrm{O}$. Sections were deparaffinized in xylene, rehydrated in a graded series of ethanol solutions and incubated with $3 \%$ hydrogen peroxide for $10 \mathrm{~min}$ at room temperature. Sections were subsequently digested with $3 \%$ pepsin for $20 \mathrm{~min}$ at $37^{\circ} \mathrm{C}$ and rinsed with PBS three times (5 min/wash). A total of $50 \mu \mathrm{l}$ of pre-hybridization solution (provided with antibodies) was added to each section, and the sections were incubated at $42^{\circ} \mathrm{C}$ for $4 \mathrm{~h}$. The pre-hybridization solution was removed and replaced with $50 \mu \mathrm{l}$ of hybridization solution with probes (or without probes for the negative control samples; provided with antibodies), and the sections were incubated at $42^{\circ} \mathrm{C}$ for $20 \mathrm{~h}$. Slides were subsequently washed ( $5 \mathrm{~min} /$ wash) twice with $2 \mathrm{X}$ sodium chloride-sodium citrate (SSC), three times with 0.5X SSC and three times with $0.02 \mathrm{X} \mathrm{SSC}$ at $37^{\circ} \mathrm{C}$. The washed sections were blocked with serum-blocking solution for $30 \mathrm{~min}$ at $37^{\circ} \mathrm{C}$ and incubated with mouse anti-digoxin antibodies against the following; BCL6 (cat. no. MK1301-h), ZEB1 (cat. no. MK3730-h) and ZEB2: (cat. no. MK3731-h; all 1:200; all Boshide Biotech Co., Ltd.) for $1 \mathrm{~h}$ at $37^{\circ} \mathrm{C}$, following which they were washed with PBS three times (5 min/wash). Sections were subsequently incubated with streptavidin-biotin-peroxidase complex solution (provided with antibodies) for $20 \mathrm{~min}$ at $37^{\circ} \mathrm{C}$, washed with PBS three times ( $5 \mathrm{~min} /$ wash) and further incubated with biotin-peroxidase solution for $20 \mathrm{~min}$ at $37^{\circ} \mathrm{C}$ (provided with antibodies). Sections were washed three times with PBS (5 min/wash), stained with 3,3'-diaminobenzidine (DAB) solution for $5 \mathrm{~min}$ at room temperature, and counterstained with hematoxylin solution for 3-5 min at room temperature.

IHC analysis. IHC analyses of BCL6, ZEB1 and ZEB2 protein expression was performed using a two-step immunohistochemical staining kit (Shanghai Changdao Biotech Co., Ltd., Shanghai, China) according to the manufacturer's protocol with rabbit anti-BCL6 polyclonal antibody $(1: 100$; TA350798; Origene Technologies, Inc., Rockville, MD, USA), mouse anti-ZEB1 monoclonal antibody (1:200; TA802313; Origene Technologies, Inc.), mouse anti-ZEB2 monoclonal antibody (1:100; TA802113; Origene Technologies, Inc.). The sections were deparaffinized in xylene and rehydrated in a graded series of ethanol solutions. For antigen retrieval, slides were heated in a microwave oven $(800 \mathrm{~W})$ in $0.01 \mathrm{M}$ sodium citrate buffer ( $\mathrm{pH}$ 6.0) for $20 \mathrm{~min}$. Slides were subsequently cooled in sodium citrate buffer and immersed in $3 \%$ hydrogen peroxide in methanol for 10 min to block endogenous peroxidase activity. Slides were washed with PBS three times ( $2 \mathrm{~min} / \mathrm{wash}$ ) and incubated with the primary antibodies (as above) at $4^{\circ} \mathrm{C}$ overnight. Subsequently, the slides were washed with PBS three times ( $2 \mathrm{~min} /$ wash), incubated 
Table I. Expression of BCL6, ZEB1 and ZEB2 mRNA in breast cancer and benign breast disease tissue.

\begin{tabular}{|c|c|c|c|c|c|c|c|}
\hline \multirow[b]{2}{*}{$\begin{array}{l}\text {-Group } \\
\text { P-value }\end{array}$} & & \multicolumn{2}{|c|}{ BCL6 expression } & \multicolumn{2}{|c|}{ ZEB1 expression } & \multicolumn{2}{|c|}{ ZEB2 expression } \\
\hline & & $\begin{array}{l}\text { Total no. o } \\
\text { n }(\%)\end{array}$ & tients & $\begin{array}{l}\mathrm{n}(\%) \\
\mathrm{P} \text {-value }\end{array}$ & & P-value & $\mathrm{n}(\%)$ \\
\hline Breast cancer & 228 & $123(53.9)$ & 0.001 & $129(56.6)$ & 0.002 & $119(52.2)$ & 0.002 \\
\hline Benign breast disease & 80 & $25(31.3)$ & & $29(36.3)$ & & $26(32.5)$ & \\
\hline
\end{tabular}

BCL6, B-cell lymphoma 6; ZEB, zinc finger E-box-binding homeobox.
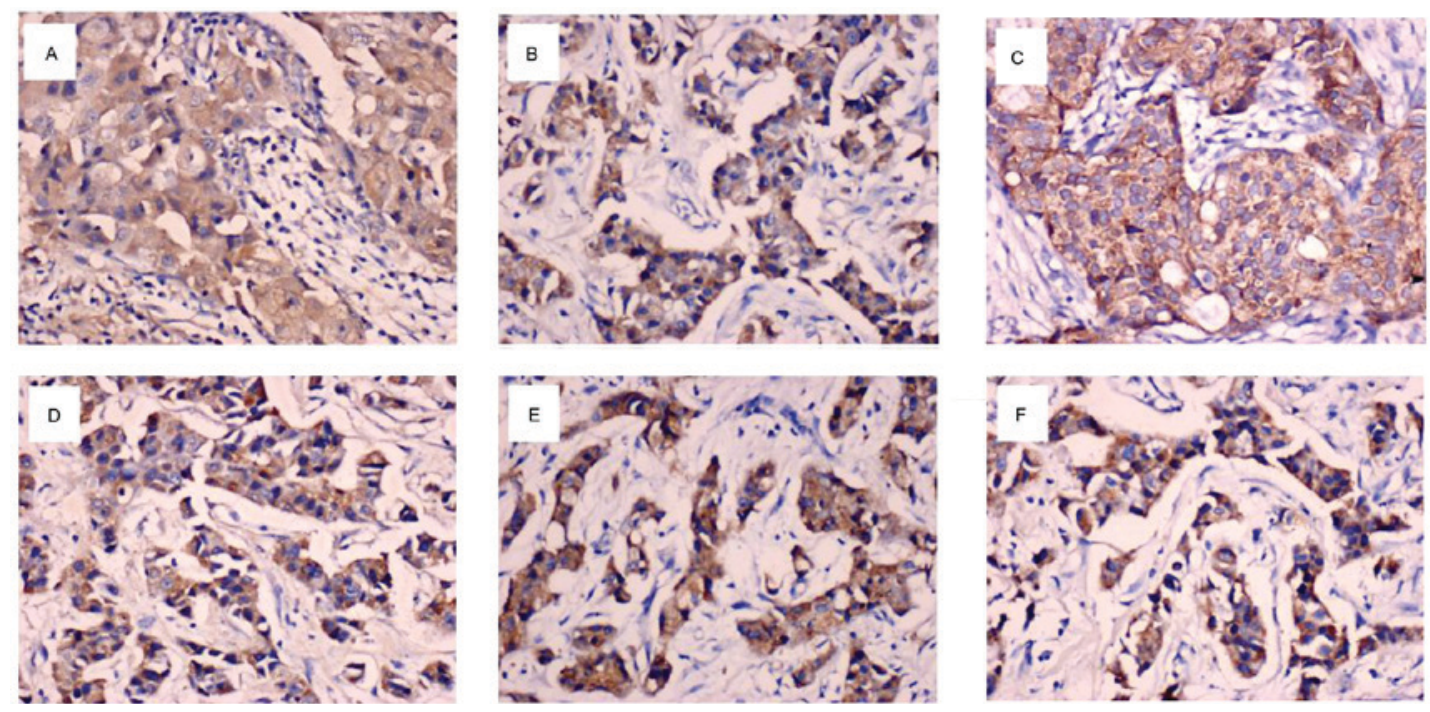

Figure 1. mRNA and protein expression of BCL6, ZEB1 and ZEB2 in breast cancer tissue specimens. In situ hybridization analysis of (A) BCL6, (B) ZEB1 and (C) ZEB2 mRNA in an invasive ductal carcinoma. Immunohistochemical staining of (D) BCL6, (E) ZEB1 and (F) ZEB2 protein in an invasive ductal carcinoma. Magnification, x400. BCL6, B-cell lymphoma 6; ZEB, zinc finger E-box-binding homeobox.

for 20 min with universal (anti-mouse/rabbit) horseradish peroxidase conjugated detection reagent (D-3004; Shanghai Changdao Biotech Co., Ltd.) at $37^{\circ} \mathrm{C}$, washed again with PBS (three times; $2 \mathrm{~min} / \mathrm{wash}$ ) and incubated with DAB solution (Shanghai Changdao Biotech Co., Ltd) for $5 \mathrm{~min}$ at room temperature. All slides were counterstained with hematoxylin for 3-5 min at room temperature. Known positive samples were used as the positive controls, and for the negative controls, the primary antibody was replaced with $0.01 \mathrm{~mol} / 1 \mathrm{PBS}$.

Scoring of stained sections. The mRNA and protein expression of BCL6, ZEB1, and ZEB2 in breast tissue specimens were reviewed and scored independently by two pathologists under double-blind conditions. The stained sections were scored according to the staining intensity and the amount of stained cells, as described previously $(18,19)$. Briefly, samples where $<10 \%$ of the breast cancer cells were stained with any intensity were considered negative for expression of the $\mathrm{mRNA} /$ protein, whereas in samples where $\geq 10 \%$ of the cancer cells were stained with any intensity were considered as positive for expression of the mRNA/protein.

Statistical analysis. All statistical analyses were performed using SPSS software (version 13.0; SPSS, Inc., Chicago,
IL, USA). The $\chi^{2}$ test was used to examine the difference in the positive expression rate of $\mathrm{mRNA}$ /protein between the groups. Kaplan-Meier survival curves were constructed to determine patient overall survival (OS) and relapse-free survival (RFS), and the variables associated with OS and RFS rates were compared with a log-rank test. Spearman's rank correlation coefficient analysis was used to determine the correlation between the expression rate of $\mathrm{mRNA} /$ protein and different clinicopathological parameters. $\mathrm{P}<0.05$ was considered to indicate a statistically significant difference.

\section{Results}

Expression of BCL6, ZEB1 and ZEB2 $\mathrm{mRNA}$ and protein is significantly increased in breast cancer tissue compared with benign breast disease tissue. The mRNA expression of BCL6, ZEB1 and ZEB2 was primarily localized to the cytoplasm and/or nucleus of breast cancer cells (Fig. 1A-C). As presented in Table I, the number of patients with mRNA expression of BCL6, ZEB1 or ZEB2 was significantly higher in the breast cancer group compared with the benign breast disease group $(\mathrm{P}=0.001,0.002$ and 0.002 , respectively).

BCL6, ZEB1 and ZEB2 proteins were predominantly expressed in the cytoplasm and/or the nucleus of the breast 
Table II. Expression of BCL6, ZEB1 and ZEB2 protein in breast cancer and benign breast disease tissue.

\begin{tabular}{|c|c|c|c|c|c|c|c|}
\hline \multirow[b]{2}{*}{ Group } & \multirow[b]{2}{*}{ Total no. of patients } & \multicolumn{2}{|c|}{ BCL6 expression } & \multicolumn{2}{|c|}{ ZEB1 expression } & \multicolumn{2}{|c|}{ ZEB2 expression } \\
\hline & & $\mathrm{n}(\%)$ & P-value & $\mathrm{n}(\%)$ & P-value & $\mathrm{n}(\%)$ & P-value \\
\hline Breast cancer & 228 & $125(54.8)$ & 0.002 & $136(59.6)$ & 0.001 & $126(55.3)$ & 0.001 \\
\hline Benign breast disease & 80 & $28(35.0)$ & & $28(35.0)$ & & $26(32.5)$ & \\
\hline
\end{tabular}

BCL6, B-cell lymphoma 6; ZEB, zinc finger E-box-binding homeobox.

$\mathbf{A}$

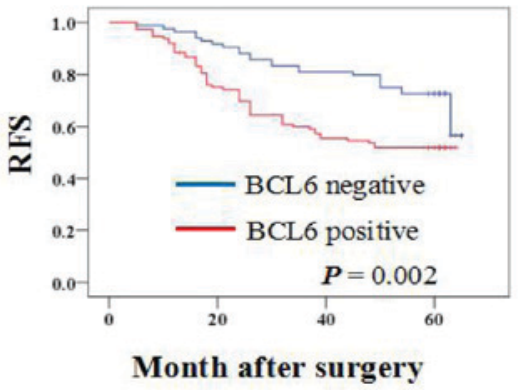

B

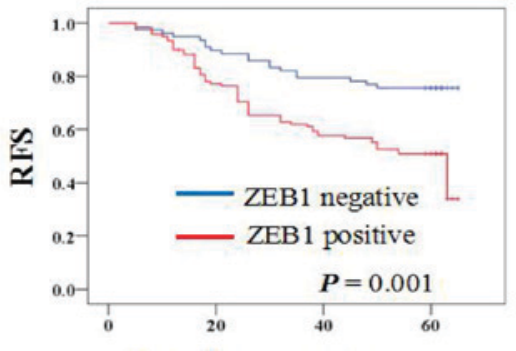

Month after surgery

C

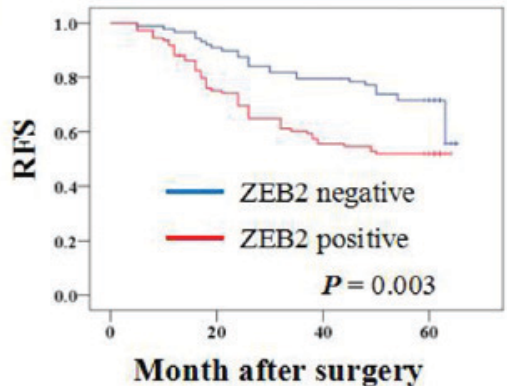

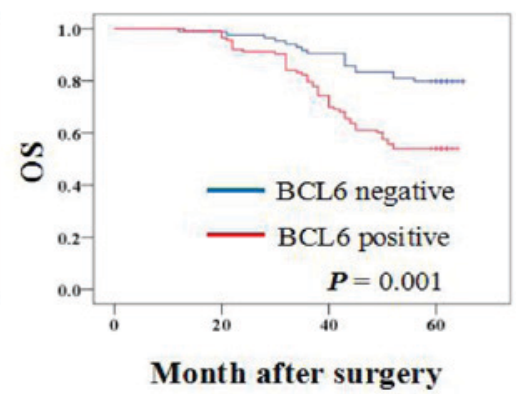

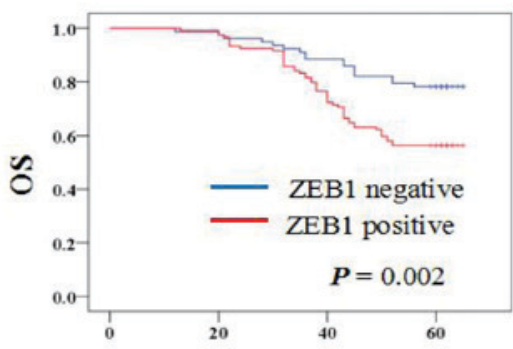

Month after surgery

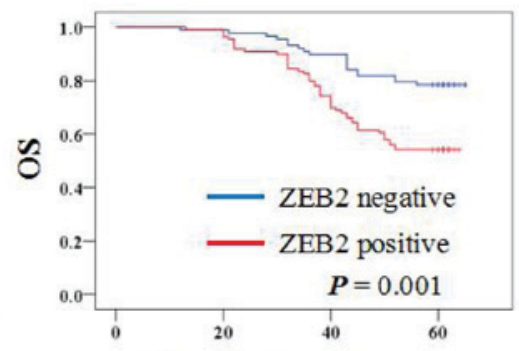

Month after surgery

Figure 2. Association between BCL6, ZEB1 and ZEB2 protein expression and the survival of patients with breast cancer. Association between (A) BCL6, (B) ZEB1 and (C) ZEB2 protein expression and RFS and OS. BCL6, B-cell lymphoma 6; ZEB, zinc finger E-box-binding homeobox; RFS, relapse-free survival; OS, overall survival.

cancer cells (Fig. 1D-F). As illustrated in Table II, protein expression of BCL6, ZEB1 or ZEB2 was significantly higher in breast cancer tissues compared with benign breast disease tissues $(\mathrm{P}=0.002,0.001$ and 0.001 , respectively).

Clinical significance of BCL6, ZEB1 and ZEB2 expression in patients with breast cancer. The association between BCL6, ZEB1 and ZEB2 mRNA expression and the clinicopathological characteristics of the patients with breast cancer was investigated (Table III). The expression of BCL6 and ZEB1 mRNA was significantly positively associated with tumor size $(\mathrm{P}=0.02$ and $\mathrm{P}=0.007$, respectively), lymph node metastasis
$(\mathrm{P}=0.038$ and $\mathrm{P}=0.028$, respectively), and a higher tumor stage $(\mathrm{P}=0.001)$. ZEB2 mRNA levels were significantly positively associated with tumor size $(\mathrm{P}=0.016)$, a higher tumor stage $(\mathrm{P}=0.002)$ and $\mathrm{c}$-erbB-2 expression $(\mathrm{P}=0.022)$. No significant associations were found between BCL6/ZEB1 mRNA expression and patient age, tumor grade, and estrogen receptor, progesterone receptor and c-erbB-2 expression. No significant associations were found between ZEB2 mRNA expression and patient age, lymph node metastasis, tumor grade, or estrogen receptor and progesterone receptor expression.

The correlation between BCL6, ZEB1 and ZEB2 protein expression and the clinicopathological features of breast 
Table III. Association between BCL6, ZEB1 and ZEB2 mRNA expression and the clinicopathological characteristics of patients with breast cancer.

\begin{tabular}{|c|c|c|c|c|c|c|c|}
\hline \multirow{2}{*}{$\begin{array}{l}\text { Clinicopathological } \\
\text { characteristic }\end{array}$} & \multirow[b]{2}{*}{ Total no. of patients } & \multicolumn{2}{|c|}{ BCL6 expression } & \multicolumn{2}{|c|}{ ZEB 1 expression } & \multicolumn{2}{|c|}{ ZEB2 expression } \\
\hline & & $\mathrm{n}(\%)$ & P-value & $\mathrm{n}(\%)$ & P-value & $\mathrm{n}(\%)$ & P-value \\
\hline \multicolumn{8}{|l|}{ Age (years) } \\
\hline$\leq 35$ & 22 & $14(63.6)$ & \multirow[t]{3}{*}{0.56} & $16(72.7)$ & \multirow[t]{3}{*}{0.266} & 14 (63.6) & \multirow[t]{3}{*}{0.341} \\
\hline $35-55$ & 131 & $71(54.2)$ & & $71(54.2)$ & & $70(53.4)$ & \\
\hline$>55$ & 75 & $38(50.7)$ & & $42(56.0)$ & & $35(46.7)$ & \\
\hline \multicolumn{8}{|l|}{ Tumor size $(\mathrm{cm})$} \\
\hline$\leq 2$ & 19 & $5(26.3)$ & \multirow[t]{3}{*}{0.02} & $5(26.3)$ & \multirow[t]{3}{*}{0.007} & $4(21.1)$ & \multirow[t]{3}{*}{0.016} \\
\hline $2-5$ & 164 & $89(54.3)$ & & $93(56.7)$ & & $89(54.3)$ & \\
\hline$>5$ & 45 & $29(64.4)$ & & $31(68.9)$ & & $26(57.8)$ & \\
\hline \multicolumn{8}{|c|}{ Lymph node metastasis } \\
\hline 0 & 82 & $36(43.9)$ & \multirow[t]{3}{*}{0.038} & $39(47.6)$ & \multirow[t]{3}{*}{0.028} & $36(43.9)$ & \multirow[t]{3}{*}{0.127} \\
\hline $1-3$ & 78 & $43(55.1)$ & & $43(55.1)$ & & $42(53.8)$ & \\
\hline$>3$ & 68 & $44(64.7)$ & & $47(69.1)$ & & $41(60.3)$ & \\
\hline \multicolumn{8}{|l|}{ Tumor grade } \\
\hline I & 19 & $8(42.1)$ & \multirow[t]{3}{*}{0.142} & $8(42.1)$ & \multirow[t]{3}{*}{0.101} & $8(42.1)$ & \multirow[t]{3}{*}{0.561} \\
\hline II & 141 & $72(51.1)$ & & $76(53.9)$ & & $73(51.8)$ & \\
\hline III & 68 & $43(63.2)$ & & 45 (66.2) & & $38(55.9)$ & \\
\hline \multicolumn{8}{|l|}{ Tumor stage } \\
\hline I & 9 & $1(11.1)$ & \multirow[t]{4}{*}{0.001} & $0(0)$ & \multirow[t]{4}{*}{0.001} & $1(11.1)$ & \multirow[t]{4}{*}{0.002} \\
\hline II & 110 & $50(45.5)$ & & $53(48.2)$ & & $50(45.5)$ & \\
\hline III & 98 & $65(66.3)$ & & $68(69.4)$ & & $59(60.2)$ & \\
\hline IV & 11 & $7(63.6)$ & & $8(72.7)$ & & $9(81.8)$ & \\
\hline \multicolumn{8}{|l|}{ Estrogen receptor } \\
\hline- & 136 & $73(53.7)$ & \multirow[t]{2}{*}{0.921} & $80(58.8)$ & \multirow[t]{2}{*}{0.406} & $78(57.4)$ & \multirow[t]{2}{*}{0.058} \\
\hline+ & 92 & $50(54.3)$ & & $49(53.3)$ & & $41(44.6)$ & \\
\hline Progesterone receptc & & & & & & & \\
\hline- & 136 & $73(53.7)$ & 0.921 & $83(61.0)$ & 0.099 & $76(55.9)$ & 0.175 \\
\hline+ & 92 & $50(54.3)$ & & $46(50.0)$ & & $43(46.7)$ & \\
\hline c-erbB-2 & & & & & & & \\
\hline Low & 148 & $75(50.7)$ & 0.178 & $79(53.4)$ & 0.185 & $69(46.6)$ & 0.022 \\
\hline High & 80 & $48(60.0)$ & & $50(62.5)$ & & $50(62.5)$ & \\
\hline
\end{tabular}

BCL6, B-cell lymphoma 6; ZEB, zinc finger E-box-binding homeobox; c-erbB-2, erb-b2 receptor tyrosine kinase 2.

cancer were also investigated. As presented in Table IV, a significant positive association was identified between BCL6 protein expression and tumor size $(\mathrm{P}=0.019)$, lymph node metastasis $(\mathrm{P}=0.003)$, a higher tumor grade $(\mathrm{P}=0.01)$, a higher tumor stage $(\mathrm{P}=0.001)$ and $\mathrm{c}$-erbB-2 expression $(\mathrm{P}=0.023)$. ZEB1 and ZEB2 protein expression were significantly positively associated with tumor size $(\mathrm{P}=0.02$ and $\mathrm{P}=0.007$, respectively), lymph node metastasis $(\mathrm{P}=0.001$ and $\mathrm{P}=0.008$, respectively) and a higher tumor stage $(\mathrm{P}=0.001$; Table IV). Furthermore, a significant positive association was observed between ZEB2 protein expression and c-erbB-2 expression $(\mathrm{P}=0.03)$. No significant associations were identified between BCL6 protein expression and patient age, estrogen receptor expression or progesterone receptor expression. No significant associations were observed between ZEB1 and ZEB2 protein expression and patient age, tumor grade, estrogen receptor expression or and progesterone receptor expression, and there was no significant association between ZEB1 protein expression and c-erbB-2 expression.

BCL6, ZEB1 and ZEB2 protein expression is associated with a significantly lower OS and RFS of patients with breast cancer. Kaplan-Meier survival analysis was performed to determine whether BCL6, ZEB1 or ZEB2 protein expression was associated with the OS or RFS of patients with breast cancer. The results demonstrated that patients with BCL6, ZEB1 and ZEB2 protein-positive primary tumors had a significantly lower OS rate $(\mathrm{P}=0.001,0.002$ and 0.001 , respectively) and $\mathrm{RFS}$ rate $(\mathrm{P}=0.002,0.001$ and 0.003 , respectively) (Fig. 2). 
Table IV. Association between BCL6, ZEB1 and ZEB2 protein expression an the clinicopathological characteristics of patients with breast cancer.

\begin{tabular}{|c|c|c|c|c|c|c|c|}
\hline \multirow{2}{*}{$\begin{array}{l}\text { Clinicopathological } \\
\text { characteristic }\end{array}$} & \multirow[b]{2}{*}{ Total no. of patients } & \multicolumn{2}{|c|}{ BCL6 expression } & \multicolumn{2}{|c|}{ ZEB1 expression } & \multicolumn{2}{|c|}{ ZEB2 expression } \\
\hline & & $\mathrm{n}(\%)$ & P-value & $\mathrm{n}(\%)$ & P-value & $\mathrm{n}(\%)$ & P-value \\
\hline \multicolumn{8}{|l|}{ Age (years) } \\
\hline$\leq 35$ & 22 & $15(68.2)$ & 0.288 & $16(72.7)$ & 0.334 & $13(59.1)$ & 0.902 \\
\hline $35-55$ & 131 & $67(51.1)$ & & $74(56.5)$ & & $71(54.2)$ & \\
\hline$>55$ & 75 & $43(57.3)$ & & $46(61.3)$ & & $42(56.0)$ & \\
\hline \multicolumn{8}{|l|}{ Tumor size $(\mathrm{cm})$} \\
\hline$\leq 2$ & 19 & $5(26.3)$ & 0.019 & $6(31.6)$ & 0.02 & $4(21.1)$ & 0.007 \\
\hline $2-5$ & 164 & $91(55.5)$ & & $99(60.4)$ & & $95(57.9)$ & \\
\hline$>5$ & 45 & $29(64.4)$ & & $31(68.9)$ & & $27(60.0)$ & \\
\hline \multicolumn{8}{|c|}{ Lymph node metastasis } \\
\hline 0 & 82 & $34(41.5)$ & 0.003 & $36(43.9)$ & 0.001 & $36(43.9)$ & 0.008 \\
\hline $1-3$ & 78 & $44(56.4)$ & & $49(62.9)$ & & $43(55.1)$ & \\
\hline$>3$ & 68 & $47(69.1)$ & & $51(75.0)$ & & $47(69.1)$ & \\
\hline \multicolumn{8}{|l|}{ Tumor grade } \\
\hline I & 19 & $6(31.6)$ & 0.01 & $10(52.6)$ & 0.391 & $7(36.8)$ & 0.15 \\
\hline II & 141 & $73(51.8)$ & & $81(57.4)$ & & 77 (54.6) & \\
\hline III & 68 & $46(67.6)$ & & $45(66.2)$ & & $42(61.8)$ & \\
\hline \multicolumn{8}{|l|}{ Tumor stage } \\
\hline I & 9 & $1(11.1)$ & 0.001 & $1(11.1)$ & 0.001 & $1(11.1)$ & 0.001 \\
\hline II & 110 & $49(44.5)$ & & $51(46.4)$ & & $49(44.5)$ & \\
\hline III & 98 & $67(68.4)$ & & $75(76.5)$ & & $68(69.4)$ & \\
\hline IV & 11 & $8(72.7)$ & & $9(81.8)$ & & $8(72.7)$ & \\
\hline \multicolumn{8}{|l|}{ Estrogen receptor } \\
\hline- & 136 & $78(57.4)$ & 0.351 & $83(61.0)$ & 0.605 & $81(59.6)$ & 0.113 \\
\hline+ & 92 & $47(51.1)$ & & $53(57.6)$ & & $45(48.9)$ & \\
\hline \multicolumn{8}{|c|}{ Progesterone receptor } \\
\hline- & 136 & $80(58.8)$ & 0.14 & $88(64.7)$ & 0.058 & $80(58.8)$ & 0.189 \\
\hline+ & 92 & 45 (48.9) & & $48(52.2)$ & & $46(50.0)$ & \\
\hline \multicolumn{8}{|l|}{ c-erbB-2 } \\
\hline Low & 148 & $73(49.3)$ & 0.023 & $82(55.4)$ & 0.076 & $74(50.0)$ & 0.03 \\
\hline High & 80 & $52(65.0)$ & & $54(67.5)$ & & $52(65.0)$ & \\
\hline
\end{tabular}

BCL6, B-cell lymphoma 6; ZEB, zinc finger E-box-binding homeobox; c-erbB-2, erb-b2 receptor tyrosine kinase 2.

Correlation between BCL6, ZEB1 and ZEB2 expression in breast cancer tissues. Spearman's rank correlation coefficient analysis demonstrated that BCL6 mRNA expression was positively correlated with ZEB1 $\left(r_{\mathrm{s}}=0.326 ; \mathrm{P}<0.001\right)$ and ZEB2 $\left(r_{\mathrm{s}}=0.382 ; \mathrm{P}<0.001\right)$ mRNA expression (data not shown). A significant correlation was also identified between BCL6 protein expression and ZEB1 $\left(r_{\mathrm{s}}=0.449 ; \mathrm{P}<0.001\right)$ and ZEB2 $\left(r_{\mathrm{s}}=0.669 ; \mathrm{P}<0.001\right)$ protein expression (data not shown).

\section{Discussion}

BCL6 is a transcriptional repressor that serves an oncogenic role in B cell lymphoma (20). Through binding to specific DNA sequences, BCL6 regulates the transcription of a variety of genes associated with B-cell development, differentiation and activation, and, due to a functional mutation in the BCL6 promoter, BCL6 is overexpressed in patients with diffuse large B cell lymphoma (DLBCL) (21). It has been suggested that BCL6 may serve a role in the progression of breast cancer. BCL6 is expressed in the mammary epithelial cells of non-pregnant animals, in addition to during early pregnancy (8). Although BCL6 protein is rarely expressed in the normal mammary epithelium, it is overexpressed in breast cancers, particularly high-grade ductal breast cancer (22). ZEB1 and ZEB2 are members of the ZEB family, and several lines of evidence have suggested that ZEB1 and ZEB2 are inducers of EMT through regulating E-cadherin expression, consequently promoting cancer progression (12,23-25). EMT is a characteristic feature of aggressive metastatic cancers, and is important for invasion and metastasis during cancer progression $(26,27)$. 
In the present study, it was demonstrated that the mRNA and protein expression of BCL6, ZEB1 and ZEB2 were significantly higher in breast cancer tissues compared with benign breast disease tissues. In addition, BCL6, ZEB1 and ZEB2 expression was significantly positively associated with tumor size, lymph node metastasis and a higher tumor stage. Furthermore, Kaplan-Meier survival analyses revealed an association between BCL6, ZEB1 and ZEB2 protein expression and poor OS and RFS in patients with breast cancer. These data suggest that BCL6, ZEB1 and ZEB2 serve important roles in breast cancer progression, and may therefore be useful biomarkers for predicting patient survival.

Previous studies have reported altered expression of BCL6, ZEB1 and ZEB2 in several types of tumor (28-30). Overexpression of BCL6 has been observed in $40 \%$ of patients with DLBCL (28), and Jia et al (29) reported that overexpression of ZEB1 may be associated with the occurrence and development, in addition to the invasion and metastasis, of gastric carcinoma. Prislei et al (30) demonstrated that ZEB2 serves a role in ovarian cancer cell migration and identified that high expression of ZEB2 mRNA was significantly correlated with poor prognosis (OS and progression-free survival) in a series of 143 patients with ovarian cancer. These data are consistent with the results of the present study. However, Pinto et al (18) reported that BCL6 protein expression was significantly lower in metastatic lymph node tumors compared with the corresponding primary breast cancer. The reason for this is unclear and requires further research.

The results of the present study identified that the mRNA and protein expression of BCL6 was significantly positively associated with ZEB1 and ZEB2 mRNA and protein expression in breast cancer tissues. This suggests that BCL6 is a potential regulator of ZEB1 and ZEB2. Although the roles of BCL6, ZEB1 and ZEB2 in different types of tumor have been widely studied, little is currently known about their association with one another. Yu et al (13) investigated the effects of BCL6 in the regulation of EMT and the mechanisms underlying this, and reported that BCL6 promoted EMT via enhancing the ZEB1-mediated transcriptional repression of E-cadherin in breast cancer cells. Brabletz et al (31) identified that ZEB1 and miR-200 family members repressed the expression of one another in a reciprocal feedback loop; this loop reportedly controls the Notch signaling pathway in cancer cells. Nishijima et al (32) suggested that the miR200/ZEB axis regulates sensitivity to nintedanib in non-small cell lung cancer cells. Gregory et al (33) reported a strong protein and mRNA expression correlation between ZEB family members and transforming growth factor- $\beta$, and negative mRNA expression correlations between miR-200 and TGF- $\beta$, and miR-200 and ZEB family members, in invasive ductal carcinomas. However, further studies are required to determine whether there is a correlation between BCL6 and miR-200.

In conclusion, the results of the present study indicate that BCL6, ZEB1 and ZEB2 are potential biomarkers for predicting the invasion, metastasis and prognosis of breast cancer, and suggest that BCL6 may serve as a regulator of the ZEB family (ZEB1 and ZEB2). Further studies are warranted to elucidate the regulatory mechanisms underlying the association between BCL6 and ZEB1/ZEB2 expression.

\section{Acknowledgements}

The present study was supported by the Fifth Cycle Of Medical Key Specialist Construction Funds Of Hefei [grant no. 2016 (256)] and the Indigenous Innovation Policies Program of Hefei [grant no. 2014 (71)-7)].

\section{References}

1. Siegel RL, Miller KD and Jemal A: Cancer Statistics, 2017. CA Cancer J Clin 67: 7-30, 2017.

2. Siegel RL, Miller KD and Jemal A: Cancer statistics, 2016. CA Cancer J Clin 66: 7-30, 2016.

3. Nola S, Sin S, Bonin F, Lidereau R and Driouch K: A methodological approach to unravel organ-specific breast cancer metastasis. J Mammary Gland Biol Neoplasia 17: 135-145, 2012.

4. Wu Q, Liu X, Yan H, He YH, Ye S, Cheng XW, Zhu GL, Wu WY, Wang XN, Kong XJ, et al: B-cell lymphoma 6 protein stimulates oncogenicity of human breast cancer cells. BMC Cancer 14: 418, 2014.

5. Yan H, Zhao M, Huang S, Chen P, Wu WY, Huang J, Wu ZS and Wu Q: Prolactin inhibits BCL6 expression in breast cancer cells through a microRNA-339-5p-dependent pathway. J Breast Cancer 19: 26-33, 2016

6. Walker SR, Liu S, Xiang M, Nicolais M, Hatzi K, Giannopoulou E, Elemento O, Cerchietti L, Melnick A and Frank DA: The transcriptional modulator BCL6 as a molecular target for breast cancer therapy. Oncogene 34: 1073-1082, 2015.

7. Shaffer AL, Yu X, He Y, Boldrick J, Chan EP and Staudt LM: BCL-6 represses genes that function in lymphocyte differentiation, inflammation, and cell cycle control. Immunity 13: 199-212, 2000.

8. Logarajah S, Hunter P, Kraman M, Steele D, Lakhani S, Bobrow L, Venkitaraman A and Wagner S: BCL-6 is expressed in breast cancer and prevents mammary epithelial differentiation. Oncogene 22: 5572-5578, 2003.

9. Eger A, Aigner K, Sonderegger S, Dampier B, Oehler S, Schreiber M, Berx G, Cano A, Beug H and Foisner R: DeltaEF1 is a transcriptional repressor of E-cadherin and regulates epithelial plasticity in breast cancer cells. Oncogene 24: 2375-2385, 2005.

10. Comijin J, Berx G, Vermassen P, Verschueren K, van Grunsven L, Bruyneel E, Mareel M, Huylebroeck D and van Roy F: The two-handed $\mathrm{E}$ box binding zinc finger protein SIP1 downregulates E-cadherin and induces invasion. Mol Cell 7: 1267-1278, 2001.

11. Guarino M, Rubino B and Ballabio G: The role of epithelial-mesenchymal transition in cancer pathology. Pathology 39: 305-318, 2007.

12. Gonzalez DM and Medici D: Signaling mechanisms of the epithelial-mesenchymal transition. Sci Signal 7: re8, 2014.

13. Yu JM, Sun W, Hua F, Xie J, Lin H, Zhou DD and Hu ZW: BCL6 induces EMT by promoting the ZEB1-mediated transcription repression of E-cadherin in breast cancer cells. Cancer Lett 365: 190-200, 2015.

14. Tavassoli FA and Devilee P (eds): World Health Organization Classification Of Tumors: Pathology And Genetics Of Tumors Of The Breast And Female Genital Organs. Lyon, IARC Press, pp13-59, 2003.

15. Sobin LH and Wittekind C: TNM classification of malignant tumours. 6th edition. New York, Wiley, 2002.

16. Yoder BJ, Tso E, Skacel M, Pettay J, Tarr S, Budd T, Tubbs RR, Adams JC and Hicks DG: The expression of fascin, an actin-bundling motility protein, correlates with hormone receptor-negative breast cancer and a more aggressive clinical course. Clin Cancer Res 11: 186-192, 2005.

17. Wolff AC, Hammond ME, Hicks DG, Dowsett $M$, McShane LM, Allison KH, Allred DC, Bartlett JM, Bilous M, Fitzgibbons $\mathrm{P}$, et al: Recommendations for human epidermal growth factor receptor 2 testing in breast cancer: American Society of Clinical Oncology/College of American Pathologists clinical practice guideline update. J Clin Oncol 31: 3997-4013, 2013.

18. Pinto AE, André S, Silva G, Vieira S, Santos AC, Dias S and Soares J: BCL-6 oncoprotein in breast cancer: Loss of expression in disease progression. Pathobiology 76: 235-242, 2009. 
19. Kurahara H, Takao S, Maemura K, Mataki Y, Kuwahata T, Maeda K, Ding Q, Sakoda M, Iino S, Ishigami S, et al: Epithelial-mesenchymal transition and mesenchymal-epithelial transition via regulation of ZEB-1 and ZEB-2 expression in pancreatic cancer. J Surg Oncol 105: 655-661, 2012.

20. Basso K and Dalla-Favera R: Roles of BCL6 in normal and transformed germinal center B cells. Immunol Rev 247: 172-183, 2012.

21. Duan S, Cermak L, Pagan JK, Rossi M, Martinengo C, di Celle PF, Chapuy B, Shipp M, Chiarle R and Pagano M: FBXO11 targets BCL6 for degradation and is inactivated in diffuse large B-cell lymphomas. Nature 481: 90-93, 2012.

22. Bos R, van Diest PJ, van der Groep P, Greijer AE, Hermsen MA, Heijnen I, Meijer GA, Baak JP, Pinedo HM, van der Wall E and Shvarts A: Protein expression of B-cell lymphoma gene 6 (BCL-6) in invasive breast cancer is associated with cyclin D1 and hypoxia-inducible factor-1alpha (HIF-1alpha). Oncogene 22: 8948-8951, 2003.

23. You J, Li Y, Fang N, Liu B, Zu L, Chang R, Li X and Zhou Q: MiR-132 suppresses the migration and invasion of lung cancer cells via targeting the EMT regulator ZEB2. PLoS One 9: e91827, 2014.

24. Xue M, Pang H, Li X, Li H, Pan J and Chen W: Long non-coding RNA urothelial cancer-associated 1 promotes bladder cancer cel migration and invasion by way of the hsa-miR-145-ZEB1/2-FSCN1 pathway. Cancer Sci 107: 18-27, 2016.

25. Wu DI, Liu L, Ren C, Kong D, Zhang P, Jin X, Wang T and Zhang G: Epithelial-mesenchymal interconversions and the regulatory function of the ZEB family during the development and progression of ovarian cancer. Oncol Lett 11: 1463-1468, 2016.
26. Bates RC and Mercurio AM: The epithelial-mesenchymal transition (EMT) and colorectal cancer progression. Cancer Biol Ther 4: 365-370, 2005

27. Xue C, Plieth D, Venkov C, Xu C and Neilson EG: The gatekeeper effect of epithelial-mesenchymal transition regulates the frequency of breast cancer metastasis. Cancer Res 63: 3386-3394, 2003.

28. Lossos IS, Jones CD, Warnke R, Natkunam Y, Kaizer H, Zehnder JL, Tibshirani R and Levy R: Expression of a single gene, BCL-6, strongly predicts survival in patients with diffuse large B-cell lymphoma. Blood 98: 945-951, 2001.

29. Jia B, Liu H, Kong Q and Li B: Overexpression of ZEB1 associated with metastasis and invasion in patients with gastric carcinoma. Mol Cell Biochem 366: 223-229, 2012.

30. Prislei S, Martinelli E, Zannoni GF, Petrillo M, Filippetti F, Mariani M, Mozzetti S, Raspaglio G, Scambia G and Ferlini C: Role and prognostic significance of the epithelial-mesenchymal transition factor ZEB2 in ovarian cancer. Oncotarget 6 : 18966-18979, 2015.

31. Brabletz S, Bajdak K, Meidhof S, Burk U, Niedermann G, Firat E, Wellner U, Dimmler A, Faller G, Schubert J and Brabletz T: The ZEB1/miR-200 feedback loop controls Notch signalling in cancer cells. EMBO J 30: 770-782, 2011.

32. Nishijima N, Seike M, Soeno C, Chiba M, Miyanaga A, Noro R, Sugano T, Matsumoto M, Kubota K and Gemma A: MiR-200/ZEB axis regulates sensitivity to nintedanib in non-small cell lung cancer cells. Int J Oncol 48: 937-944, 2016.

33. Gregory PA, Bracken CP, Smith E, Bert AG, Wright JA, Roslan S, Morris M, Wyatt L, Farshid G, Lim YY, et al: An autocrine TGF-beta/ZEB/miR-200 signaling network regulates establishment and maintenance of epithelial-mesenchymal transition. Mol Biol Cell 22: 1686-1698, 2011. 